\title{
Rolling Deformations and Residual Stresses of Large Circular Saw Body
}

\author{
Bolesław Porankiewicz ${ }^{1}$, Jari Parantainen ${ }^{2}$, Karolina Ostrowska ${ }^{3}$ \\ ${ }^{1}$ University of Zielona Góra, Zielona Góra, Poland \\ ${ }^{2}$ Stresstech OY, Vaajakoski, Finland \\ ${ }^{3}$ Poznań University of Technology, Poznań, Poland \\ E-mail:poranek@amu.edu.pl,jari.parantainen@stresstech.fi,karolina.ostra@gmail.com \\ Received May 21, 2010; revised July 19, 2010; accepted September 5, 2010
}

\begin{abstract}
Rolling path squeezes and rolling residual stresses of large diameter circular saw body for wood, generated by rolling pressure from 10 up to 120 bar were examined. X-ray diffraction, Barkhausen noise $(B N)$ and Full Width of the peak at a Half Maximum $(F W H M)\left({ }^{\circ}\right)$ methods for evaluation of residual stresses were used. Dependencies of a tangential rolling residual stresses inside rolling paths upon rolling pressure $p$ (bar) and rolling area $A\left(\mathrm{~mm}^{2}\right)$ were evaluated. The rolling pressure, as large as $60 \mathrm{bar}$, resulting in the rolling squeeze as high as $0.04 \mathrm{~mm}^{2}$, and, tangential residual compression stresses inside a rolling path, as large as $\sigma_{T I}=$ $-822 \mathrm{MPa}$, was considered to be the largest for the practical application.
\end{abstract}

Keywords: Circular Saw, Rolling Squeeze Area, Rolling Squeeze Width, Rolling Squeeze Depth, Rolling Pressure, Tangential Rolling Residual Stresses, Radial Rolling Residual Stresses, X-Ray Diffraction, Barkhausen Noise, FWHM.

\section{Introduction}

Circular saws rolling use to be widely applied method of initial tensioning, aiming at increase the dynamic stiffness of saws for wood and secondary wood products machining. This method is not devoid of negative aspects. It has to be mentioned that the rolling may cause necessity to correct flatness when stresses distribution inside a circular saw body is not correct. There are several ways of evaluation of rolling effects, like: - a depth $d(\mathrm{~mm})$, an area $A\left(\mathrm{~mm}^{2}\right)$ of a rolling path, - a light gap between deformed blade and a straight edge rule [1], - a static stiffness [2], - a compression stresses inside a rolling path. However, as a final measure of effect of a saw blade rolling was recognized as a shift of natural frequencies and critical rotational speeds of several initial vibration modes $[3,4]$. From available literature important facts concerning with amount of tensioning necessary to insert in a saw blades of different dimension and for different applications in order to get stable work are known [5-7]. However, from practical point of view there are lack of informations in published works, about rolling pressures used, plastic squeeze of circular saw body material and rolling path shape [2]. The goals of actual work were: to exam the amount of squeeze in a circular saw body using different rolling pressures $p$ (bar) and measure presence of residual stresses using three different techniques.

\section{Experimental}

The circular saw body, before cemented carbide tips soldering, by thickness of $t_{S}=3 \mathrm{~mm}$ and by diameter of $D=620 \mathrm{~mm}$, made of $75 \mathrm{Cr} 1$ low alloy steel, was rolled in industrial conditions, with use of rolling machine Arga T08 on 12 different paths. The pressure $p$ (bar) in hydraulic cylinder, was from 10 bar (145.04 psi) up to 120 bar (1740.456 psi) with of 10 bar (145.04 psi) increment. The depth $d(\mathrm{~mm})$ and width $w(\mathrm{~mm})$ of a rolling paths were measured with use of profilografometer type ME10. X-ray residual stress measurements contained totally 25 points from the blade using modified $\mathrm{d}\left(\sin ^{2} \psi\right)[8]$ method. X-ray measurements were performed using XSTRESS3000 diffractometer manufactured by Stresstech OY, by following conditions:

Device: G2R (\#7147)

Radiation source: $\mathrm{CrKa}$

Diffraction line angular position, 
according to Bragg's law 2q: $156.4^{\circ}$ (211)

Spot size: $1 \mathrm{~mm}$ and $2 \mathrm{~mm}$

Exposure time: $20 \mathrm{~s}$ and $8 \mathrm{~s}$

Tilt angles: $4 / 4$ tilts, $\psi<-40^{\circ} / 40^{\circ}>; \psi$ oscillation $\pm 5^{\circ}$

Young's modulus: $211000 \mathrm{MPa}$

Poisson ratio: 0.3

Calculation: Cross correlation, constant background [8].

Measurement method: Modified $d\left(\sin ^{2} \psi\right)$ [8]

The measurement directions can be seen in Figure 1. The angle of $\varphi=0^{\circ}$ corresponds to tangential direction and of $\varphi=90^{\circ}$ to radial direction.

The $F W H M\left({ }^{\circ}\right)$ values were calculated from the x-ray diffraction peaks in order to get indirect information for the presence of the residual stresses through micro hardness and plastic deformation (dislocation density) layer. The $F W H M\left({ }^{\circ}\right)$ values are average ones from $\psi\left({ }^{\circ}\right)$ angles examined.

The $B N$ measurements were performed in the same radial path, like during the X-ray diffraction ones, using following conditions:

Device: Rollscan 300

Sensor: S1-138

Magnetizing voltage: $4.0 \mathrm{Vpp}$

Magnetizing frequency: $100 \mathrm{~Hz}$

Analyzing frequency: $70-200 \mathrm{kHz}$

Higher hardness and/or compressive stresses decrease the $B N$ and vice versa [9]. It has to be mentioned that using the $B N$ itself was not possible to evaluate absolute values of residual stresses.

Outside rolling paths Rockwell hardness was measured (according to PN-EN ISO 6508 standard) with preliminary load of $98 \mathrm{~N}$ and total load of $1471 \mathrm{~N}$, in places shown in Figure 2, by 5 repetitions. For every place outside rolling paths an average value and standard deviation were calculated.

\section{Results and Discussion}

The rolling squeeze cross section shape for the largest rolling pressure, shown in Figure 3, was approximated with use of a second order polynomial function $d=f\left(\mathrm{a}_{1}+\right.$ $\left.\mathrm{a}_{2} \cdot w_{i}+\mathrm{a}_{3} \cdot w_{i}^{2}\right)$. It was evaluated by a Formula (1) with correlation coefficient $R$ and standard deviation $S_{D}(\mathrm{~mm})$, as large as 0.91 and $0.0067 \mathrm{~mm}$ respectively.

$$
d=0.010209-0.037531 \cdot w_{i}+0.00709 \cdot w_{i}^{2}(\mathrm{~mm})
$$

In the rolling squeeze cross section shape, several upcasts can be seen, what indicated possible wear of rolls and/or bearings in the rolling machine. The depth and width of the largest up-cast were as large as $11.4 \mu \mathrm{m}$ and $590 \mu \mathrm{m}$ respectively. Results of measurements of rolling squeeze depth $d(\mathrm{~mm})$ and width $w(\mathrm{~mm})$ were collected in Table 1 and illustrated in Figure $\mathbf{4}$ and Figure 5, re-spectively.

From Figure 4 it can be seen that rolling squeeze depth $d(\mathrm{~mm})$ increased with growth of the rolling pressure $p$ (bar) with rather large dispersion. The width $w$ $(\mathrm{mm})$ of the rolling squeezes, shown in Figure 5 increased with a growth of the rolling pressure $p$ (bar) until 50 bar. For larger pressure opposite tendency can be noticed with large dispersion. The area of the rolling squeeze $A\left(\mathrm{~mm}^{2}\right)$, shown in Figure 6 was evaluated by integrating the surface limited from the bottom by the squeeze shape and from the top by $d=0$. Large dispersion in the dependency $A=f(p)$ can also be seen especially for rolling pressure larger than $p=60$ bar, namely $p=70 \mathrm{bar}, 100 \mathrm{bar}$ and $110 \mathrm{bar}$. The reason of large dispersion of rolling depth $d(\mathrm{~mm})$, rolling width $w(\mathrm{~mm})$ and rolling squeeze $A\left(\mathrm{~mm}^{2}\right)$ was probably the wear of rolls or bearings in the rolling machine used. According to the work [6], the rolling squeeze area of $0.04 \mathrm{~mm}^{2}$, applied for a circular saw diameter $D=400 \mathrm{~mm}$, saw blade thickness $t_{S}=2 \mathrm{~mm}$ and collar diameter of $d_{C}=$ $100 \mathrm{~mm}$, resulted in 2.4, 29.4 and 14.5 times increased

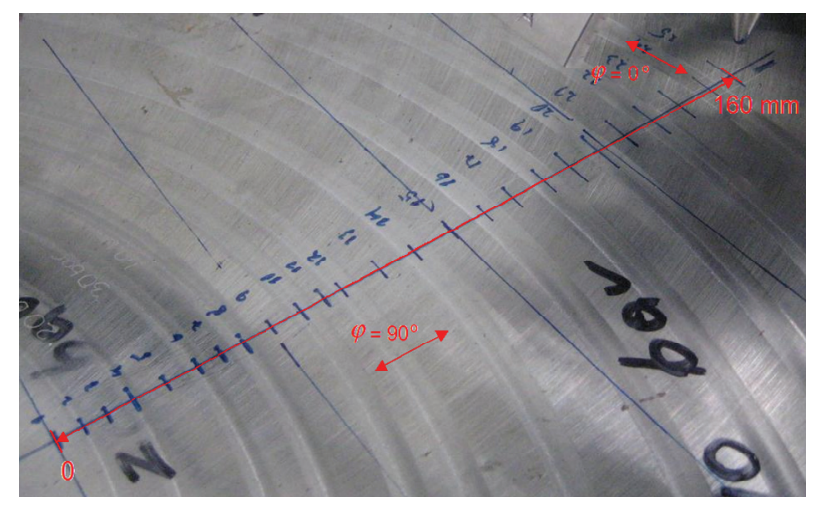

Figure 1. Direction of X-ray diffraction measurements.

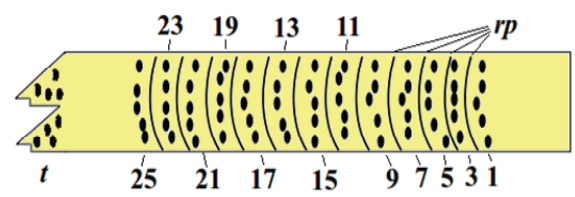

Figure 2. Places for Rockwell hardness measurements: outside rolling paths nos. $1-25, t$ - tooth area, $r p$ - rolling paths.

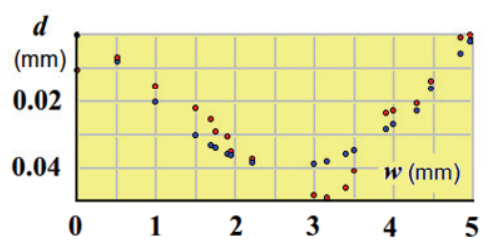

Figure 3. The observed (red) and predicted (blue) shape of cross section of the rolling path for maximum rolling pressure $p=120$ bar. 
Table 1. Rolling pressure $p$ (bar), rolling depth $d(\mathrm{~mm})$, rolling width $w(\mathrm{~mm})$, rolling area $A\left(\mathrm{~mm}^{2}\right)$.

\begin{tabular}{cccc}
\hline$p$ & $d$ & $w$ & $A$ \\
\hline$(\mathrm{MPa})$ & $(\mathrm{mm})$ & $(\mathrm{mm})$ & $\left(\mathrm{mm}^{2}\right)$ \\
10 & 2.02 & 3.24 & 0.0027 \\
20 & 1 & 3.95 & 0.0015 \\
30 & 3.4 & 3.9 & 0.0075 \\
40 & 5.6 & 5.48 & 0.0176 \\
50 & 9.3 & 6.33 & 0.029 \\
60 & 15.3 & 6.11 & 0.0443 \\
70 & 9.1 & 5.03 & 0.0318 \\
80 & 23.2 & 4.21 & 0.0463 \\
90 & 21.6 & 5.59 & 0.0642 \\
100 & 18.8 & 4.99 & 0.0312 \\
110 & 17.7 & 4.69 & 0.0312 \\
120 & 49 & 4.95 & 0.123 \\
\hline
\end{tabular}

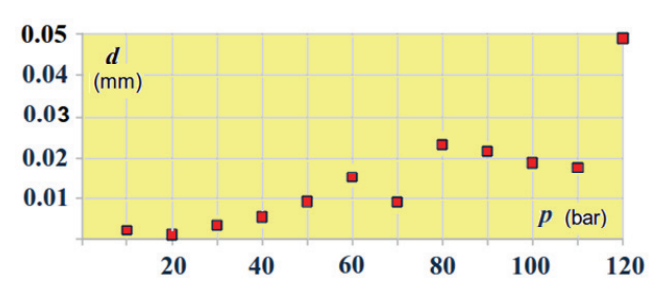

Figure 4. The average rolling path depth $d(\mathrm{~mm})$ in dependence from rolling pressure $p$ (bar).

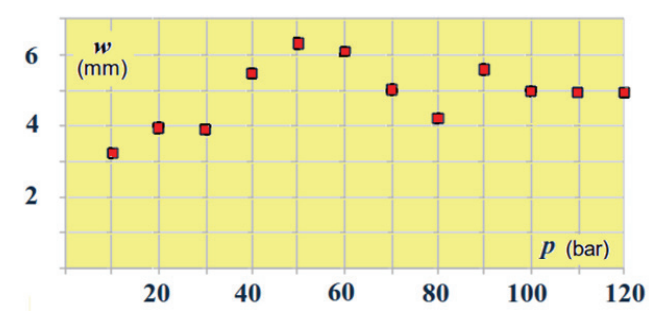

Figure 5. The average rolling path width $w(\mathrm{~mm})$ in dependence from rolling pressure $p$ (bar).

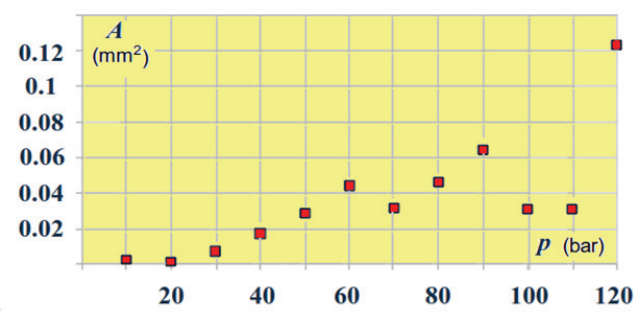

Figure 6. The average rolling path area $A\left(\mathrm{~mm}^{2}\right)$ in dependence from rolling pressure $p$ (bar).

natural frequencies of $(0,4),(0,3)$ and $(0,2)$ vibration modes respectively, while the vibration modes $(0,1)$ and $(0,0)$ natural frequencies were dropped down as much as $18 \%$ and $23 \%$ respectively by rotating speed of 3600 $\min ^{-1}$ (the first digit in the brackets ' 0 ' is the number of nodal circles, the second digit ' 4 ', ' 3 ' and ' 2 ' is the number of nodal diameters). However, in the work quoted above, no information on used rolling pressure and rolling squeeze cross section profile were given.

The residual stresses evaluated with use of the X-ray XSTRESS3000 diffractometer, inside and outside rolling paths, in both tangential $\sigma_{T I}(\mathrm{MPa})$ and radial directions $\sigma_{R I}(\mathrm{MPa})$ were shown in Figure 7. From Figure 7 it can be seen that tangential residual stresses inside rolling path $\sigma_{T I}(\mathrm{MPa})$ did not change their values smoothly according to an enlargement of the rolling pressure $p$ (bar), what was clearly seen for points nos.: 4, 8, 16 and 22 . The dispersion can also be seen for tangential residual stresses outside rolling path $\sigma_{T I}(\mathrm{MPa})$ (points nos. 5, 11, 12, 17 and 21). The reason of that might be a rather large dispersion of the residual stresses in the saw blade before rolling and/or large dispersion of rolling squeeze profile. A saw in which body are present such a large, and highly differentiated residual stresses generated during manufacturing process, has small chance for a smooth and effective work in future even if using hammering will be exactly flattened.

From Figure 7 it can be seen decreasing tendency of the tangential residual stresses outside rolling paths $\sigma_{T O}$ (MPa), with an increase of the rolling pressure $p$ (bar). Starting from point no. 11 up to point no. 25, the tangential residual stresses outside rolling paths $\sigma_{T O}(\mathrm{MPa})$ did change from compression to tensile. This was due to the total influence of rolling effect on tangential residual stresses $\Delta \sigma_{T}(\mathrm{MPa})$ along saw body radius. It was also assumed that in the saw blade examined before rolling, there were average tangential residual stresses distribution $\sigma_{T O}(\mathrm{MPa})$ with randomly distributed dispersion. The average total rolling effect, as a function of distance $\Delta \sigma_{T}=f(L)$ was approximated with statistical Formula (2) by correlation coefficient $R$ and standard deviation $S_{D}$ (MPa) as large as 0.85 and $43.6 \mathrm{MPa}$, respectively.

$$
\Delta \sigma_{T}=-79.861196+3.278002 \cdot L-0.0141832 \cdot L^{2}(\mathrm{MPa})(2)
$$

The tangential compression stresses inside rolling paths after correction $\sigma_{T I K}(\mathrm{MPa})$ were calculated as difference between the tangential compression stresses inside rolling paths $\sigma_{T I}(\mathrm{MPa})$ and the average rolling effect on the tangential residual stresses outside rolling paths $\Delta \sigma_{T}(\mathrm{MPa})$, described by Formula (2), and approximated by statistical Formula (3) in dependence upon rolling pressure $p$ (bar), by $R=0.96, S_{D}=40.8 \mathrm{MPa}$ and upon rolling squeeze area $A\left(\mathrm{~mm}^{2}\right)$ by statistical Formula (4), by $R=0.89$ and $S D=68.7 \mathrm{MPa}$.

$$
\begin{gathered}
\sigma_{T I K}=161639.174-161769.431 \cdot p^{0.001152}(\mathrm{MPa}) \\
\sigma_{T I K}=54277.706-55542.535 \cdot A^{0.00184}(\mathrm{MPa})
\end{gathered}
$$

It has to be mentioned that the dispersion of the residual tangential residual stresses in the examined saw blade 
before rolling (outside rolling paths $\sigma_{T O}(\mathrm{MPa})$ ) overshadowed examined relation.

Looking at Figure 8 it can be concluded that an increase of rolling pressure above $p>70$ bar stops the increase in tangential compression stresses inside rolling path. One can conclude that in analyzed case, the maximum rolling squeeze, giving increase tangential compression stresses inside rolling path was $A=0.04 \mathrm{~mm}^{2}$. In the published papers [1,2,5-7], there was no information about dispersion of residual stresses inside saw blades before rolling.

In examined case, after correction, the tensile stress inside saw blade before rolling, at point no. 5 was evidenced, as large as $+1.9 \mathrm{MPa}$ (Figure 8). The compression stress in point no. 21 was also very low, as small as $-5.7 \mathrm{MPa}$.

The radial residual stresses inside rolling paths $\sigma_{R I}$ (MPa) were smaller (Figure 7). They oscillated on level of about $<-332,-484>$ MPa. From Figure 7 it can also be seen the presence of a residual radial tensile stresses $\sigma_{R O}(\mathrm{MPa})$ for all points outside rolling paths. No significant correlation between residual radial tensile stresses outside rolling paths $\sigma_{R O}(\mathrm{MPa})$ and distance $L$ $(\mathrm{mm})$ along saw body radius, according to increasing rolling pressure $p$ (bar) was recognized. The residual radial stresses outside rolling paths $\sigma_{R O}(\mathrm{MPa})$ did oscillate in the range of $<+4,+266>\mathrm{MPa}$ with an error of $<35,46$ $>\mathrm{MPa}$.

It can be seen from Figure 9 that the $B N$ measurements followed general shape of stresses distribution showed in Figure 7, excluding total rolling effect $\Delta \sigma_{T}$ (MPa). The $B N$ measurements allow recognizing places with large and small values of compression stresses. Places outside rolling paths shown in Figure 9 on positions $L=108 \mathrm{~mm}, L=114 \mathrm{~mm}, L=134 \mathrm{~mm}$, and $L=$ $144 \mathrm{~mm}$ were having the largest of all the $B N$ values, what effect was not seen in Figure 7 and Figure 8. The reason of that was lower Rockwell hardness of the saw body material closer to the rim, what show Figure 10, for points nos. 17, 19, 21 and 25. According to Figure 9, the hardness in point no. 23 was too large, however, not the same measuring path for the $B N$ and the Rockwell hardness as well as large dispersion of the saw body hardness resulted in such a difference. For places outside rolling paths on positions $L=0-4 \mathrm{~mm}$ and $L=12-18 \mathrm{~mm}$, shown in Figure 9, low $B N$ values can be associated with large saw body hardness. For places inside rolling paths, on positions $L=6 \mathrm{~mm}$ and $L=22 \mathrm{~mm}$, shown in Figure 9, slightly higher the $B N$ values, can be associated with small rolling residual compression stresses. The $B N$ measurements results for places outside rolling paths shown in Figure 9 were characterized with large dispersion. The $B N$ measurements technique would be useful in manufacturing conditions, to control residual stresses distribution in saw blades after different operations. This conclusion can also be supported by the fact of many times lower price of the Rollscan 300 device in comparison to the X-ray XSTRESS3000 diffractometer. Still the priority benefit is in the time consumed in performing the measurements. The whole X-ray measurement procedure can easily last hour or two, but the $B N$ measurement is usually done in few seconds.

Results of measurements of the $F W H M\left({ }^{\circ}\right)$ outside and inside rolling, were collected in Table 2 and illustrated in Figure 11. From the plot shown in Figure 11 it can be

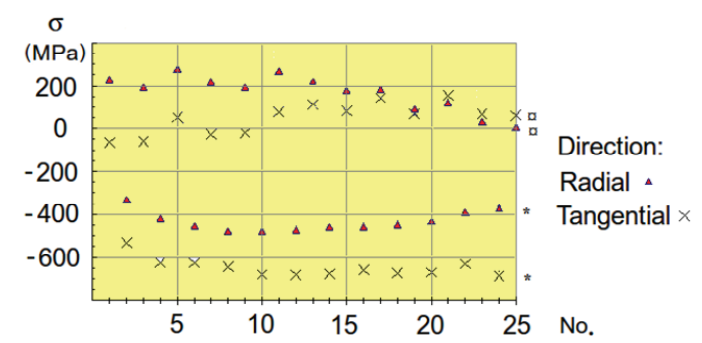

Figure 7. The plot of residual stresses $\sigma(\mathrm{MPa})$ along saw blade radius, in tangential and radial directions, * - inside and $\alpha$ - outside rolling paths.

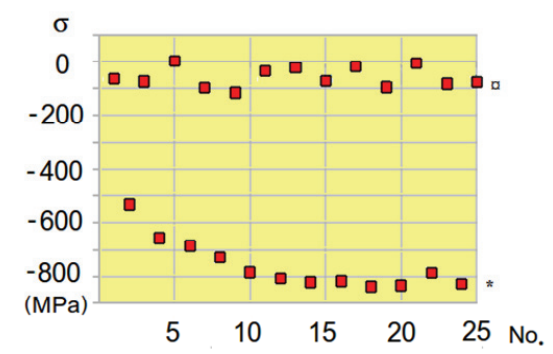

Figure 8. The plot of residual stresses in tangential direction after correction, along the saw blade radius, * - inside $\sigma_{T I}(\mathrm{MPa})$, and $\alpha$ - outside $\sigma_{T O}(\mathrm{MPa})$ rolling paths.

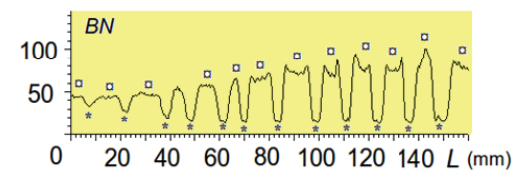

Figure 9. The plot of the Barkhausen noise along saw blade radius, * inside and outside rolling paths.

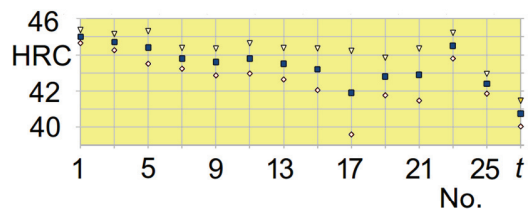

Figure 10. The plot of the Rockwell hardness of the sawbody, along saw blade radius, in points number No., outside rolling paths, $t$ - tooth area. 


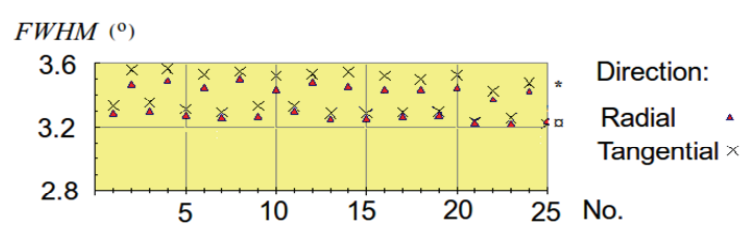

Figure 11. The plot of $F W H M\left({ }^{\circ}\right)$ along saw blade radius in tangential and radial directions, * - inside and $a$ - outside rolling paths.

seen that the $F W H M\left({ }^{\circ}\right)$ values were larger for places inside rolling paths than for places outside rolling paths, what was opposite in comparison to the $B N$ measurements results shown in Figure 9. The difference between small and large residual compression stresses inside rolling paths can not be recognized using Figure 11, what indicates that the shape of the plots from Figure 7 and Figure 11 was not followed each other. The FWHM $\left(^{\circ}\right)$ measurements allow recognizing places with large and small residual stresses, but with much lower precision if compare to the $B N$ measurements. The increase of the $F W M H\left({ }^{\circ}\right)$ values inside rolling paths might also be occurred by work hardening effect of the rolling process.

\section{Conclusions}

The experiment and measurements of rolling effects and analysis of results obtained allow concluding that:

1) It is recommended to apply the rolling pressure up to $60 \mathrm{MPa}$ by use rolling machine Arga T08, giving rolling squeeze as large as $A=0.04 \mathrm{~mm}^{2}$ and tangential residual compression stresses inside rolling paths as large as $\sigma_{T I}=-822 \mathrm{MPa}$.

2) For rolling pressure $p$ (bar) from 70 to 120 bar, no increase of the tangential compression residual stresses increase inside the rolling paths was observed.

3) For rolling pressure $p$ (bar) from 70 to 120 bar large variation of rolling squeeze depth $d(\mathrm{~mm})$ and width $w(\mathrm{~mm})$ was seen. By the largest rolling pressure $(d=$ $0.049 \mathrm{~mm}, w=4.95 \mathrm{~mm}, A=0.123 \mathrm{~mm}^{2}$ ) significant upcast of $11.4 \mu \mathrm{m}$ in depth and $590 \mu \mathrm{m}$ in the width was evidenced, indicating possible wear of rolls and/or bearings in the rolling machine.

4) Large dispersion of tangential $\sigma_{T O}(\mathrm{MPa})$ and radial $\sigma_{R O}(\mathrm{MPa})$ residual stresses outside rolling paths, added to the saw blade before rolling, with maximum value of $155 \mathrm{MPa}$ and $274 \mathrm{MPa}$ respectively was evidenced.

5) The $B N$ measurements allow recognizing the presence of small and large compression stresses inside and outside rolling paths, but this information is mixed with effect of hardness change distribution.

6) In one measuring point, outside rolling path after correction positive, residual tensile tangential stress of + 1.9 MPa was recognized.
Table 2. Stress and $F W H M\left({ }^{\circ}\right)$ values, evaluated with use of $\mathrm{X}$-ray diffractometer.

\begin{tabular}{|c|c|c|c|c|c|c|}
\hline \multirow[t]{2}{*}{$\begin{array}{l}\text { Position } \\
\text { No }\end{array}$} & \multicolumn{2}{|c|}{$\begin{array}{l}\text { Stress Tangential } \\
\qquad \varphi=0^{\circ}\end{array}$} & \multicolumn{2}{|c|}{$\begin{array}{c}\text { Stress Radial } \\
\varphi=90^{\circ}\end{array}$} & \multirow{2}{*}{$\begin{array}{c}F W H M \\
\varphi=0^{\circ}\end{array}$} & \multirow{2}{*}{$\begin{array}{c}F W H M \\
\varphi=90^{\circ}\end{array}$} \\
\hline & $(\mathrm{MPa})$ & (MPa) & (MPa) & ( MP) & & \\
\hline 1 & -64 & 10 & 225 & 46 & 3.33 & 3.28 \\
\hline 2 & -533 & 8 & -332 & 13 & 3.56 & 3.46 \\
\hline 3 & -60 & 11 & 190 & 41 & 3.35 & 3.30 \\
\hline 4 & -625 & 7 & -424 & 8 & 3.56 & 3.49 \\
\hline 5 & 51 & 13 & 274 & 39 & 3.31 & 3.27 \\
\hline 6 & -626 & 8 & -458 & 18 & 3.53 & 3.45 \\
\hline 7 & -26 & 11 & 215 & 42 & 3.29 & 3.25 \\
\hline 8 & -645 & 7 & -484 & 15 & 3.55 & 3.50 \\
\hline 9 & -19 & 12 & 189 & 46 & 3.33 & 3.26 \\
\hline 10 & -681 & 10 & -483 & 11 & 3.52 & 3.43 \\
\hline 11 & 77 & 17 & 266 & 40 & 3.33 & 3.29 \\
\hline 12 & -683 & 10 & -477 & 18 & 3.53 & 3.48 \\
\hline 13 & 113 & 12 & 217 & 40 & 3.28 & 3.25 \\
\hline 14 & -678 & 6 & -464 & 15 & 3.54 & 3.45 \\
\hline 15 & 81 & 18 & 175 & 41 & 3.28 & 3.25 \\
\hline 16 & -660 & 17 & -462 & 19 & 3.52 & 3.43 \\
\hline 17 & 144 & 20 & 181 & 40 & 3.29 & 3.26 \\
\hline 18 & -674 & 9 & -453 & 20 & 3.50 & 3.43 \\
\hline 19 & 69 & 15 & 86 & 36 & 3.29 & 3.27 \\
\hline 20 & -671 & 9 & -435 & 21 & 3.52 & 3.44 \\
\hline 21 & 155 & 21 & 115 & 35 & 3.23 & 3.22 \\
\hline 22 & -631 & 11 & -392 & 25 & 3.43 & 3.37 \\
\hline 23 & 67 & 22 & 30 & 36 & 3.26 & 3.22 \\
\hline 24 & -687 & 11 & -377 & 34 & 3.48 & 3.42 \\
\hline 25 & 59 & 26 & 4 & 28 & 3.22 & 3.24 \\
\hline
\end{tabular}

7) No significant rolling effect on radial residual stresses inside $\sigma_{R I}(\mathrm{MPa})$ and outside $\sigma_{R I}(\mathrm{MPa})$ rolling paths was seen.

\section{Acknowledgements}

The authors were grateful for the support of the Stresstech OY Company in performing X-ray diffraction and $B N$ measurements. The authors were also grateful for the support of the Poznan Networking \& Supercomputing Center (PCSS) calculation grant.

\section{References}

[1] P. F. Lister and G. S. Schajer, "The Effectiveness of the Light-Gap and Frequency Measurement Methods for Evaluating Saw Tensioning," Proceedings of 10th Wood Machining Seminar, University of California, Forest Products Laboratory, Richmond, 21-23 October 1991, pp. 68-84.

[2] R. Szymani and C. D. Mote, "Circular Saw Stiffness as a 
Measure of Tension," Forest Products Journal, Vol. 27, No. 3, 1977, pp. 28-32.

[3] J. Rhemrev and L. Trinchera, "Improving the Stability of Thin Circular Saws though Applied Research," 32nd Annual Meeting the Forest Products Research Society, Atlanta, 1978.

[4] G. S. Schajer and C. D. Mote, "Analysis of Roll Tensioning and its Influence on Circular Saw Stability," Wood Science \& Technology, Vol. 17, 1983, pp. 287-302.

[5] U. V. Münz, "Means of Testing and Designing Circular Saw Blades," Proceedings of the 13th International Wood Machining Seminar, Vancouver, 17-20 June 1997, pp. 105-116.

[6] G. S. Schajer and C. D. Mote, "Analysis of Optimal Roll
Tensioning for Circular Saw Stability," Proceedings of 7th Wood Machining Seminar, University of California Forest Products Laboratory, Richmond, 18-20 October 1982, pp. 264-283.

[7] G. S. Schajer and C. D. Mote, "Analysis of Optimal Roll Tensioning for Circular Saw Stability," Wood \& Fiber Science, Vol. 16, No. 3, 1984, pp. 323-338.

[8] P. S. Prevey, "X-Ray Diffraction Residual Stress Techniques, Metals Handbook," 10 Metals Park: American Society for Metals, 1986, pp. 380-392.

[9] R. L. Pasley, "Barkhausen Effect - An Indication of Stress," Southwest Research Institute, San Antonio, Texas, 1969. 